\begin{tabular}{|c|c|}
\hline \multirow{3}{*}{ 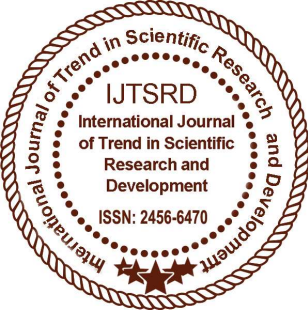 } & $\begin{array}{l}\text { International Journal of Trend in Scientific } \\
\text { Research and Development (IJTSRD) }\end{array}$ \\
\hline & International Open Access Journal \\
\hline & ISSN No: 2456 - 6470 | www.ijtsrd.com | Volume - 2 | Issue - 4 \\
\hline
\end{tabular}

\title{
Productivity Improvement in a Sewing Line Through Line Balancing in a Garment Manufacturing Company in the Philippines
}

\author{
Amaya, Flocerfida $\mathrm{L}^{1}$, Delos Santos, Rafael, $\mathrm{A}^{2}$, Tenorio, Rodolfo Jr. $\mathbf{V}^{2}$ \\ ${ }^{1}$ Dean, College of Engineering, ${ }^{2}$ Industrial Engineer \\ University of Perpetual Help System Laguna, City of Binan, Laguna, Philippines
}

\begin{abstract}
In any manufacturing company, productivity in terms of quality and cost required in doing the operation is the topmost priority to be considered. Productivity improvement was studied through the use of time and motion study and line balancing concept in one of the clusters of a sewing line in a garment manufacturing company. Series of observations in the line and direct interviews among the regular personnel involved in the operation were done including the sewers, pressers, and supervisors in charge of the assembly line. It was noted that the average productivity rate of the selected assembly line was only seventy-one (71) percent way down below from their target output. Based on the findings of the study, plant layout was one of the contributing factors that causes bottleneck in the assembly line particularly in the pairing and aligning of cut goods. Task time involved in each process was studied and computed based on optimal number of manpower and expected productivity rate. In effect, combining the processes of pairing and aligning of cut goods in one line contributes great impact in reduction of machine requirements per process to improve the productivity rate of the company.
\end{abstract}

Keywords: Productivity, Time and Motion Study, Line Balancing

\section{INTRODUCTION}

Productivity pertained to the effectiveness of a certain individual or an organization to produce goods or to render certain service over a period of time. Different approaches of productivity improvement were done from previous citations of Propster, Marz, Reinhart and Intra (2015), where dynamic balancing is done for a high productivity mixed -model assembly line to handle the different assembly times of the variants. According to Chowdury MD. Luthfur Rahman (2010), the greatest problems the operation department is facing today are the high level of boredom, absenteeism, personnel turnover, and dissatisfaction among assembly-line workers. Luthfur Rahman (2010) worked in providing flexibility in assembly system wherein existing assembly line was redesigned considering possible alternatives while Bhagirath (2015) focused on the assessment of manpower efficiency to increase workers productivity for higher workers efficiency rate and performance. Commonly, previous studies focus on the worker or human factor improving productivity in a production line. The researchers of previous studies broke down the human factors and rearrange the processes in each line in order to balance the assembly line.

This study aims to produce higher productivity in one of the clusters of a sewing line in a garment manufacturing company. Analysis with the existing conditions were done such as human factors, state of the process, nature of the work, design of the process, requirement of the products and other more unseen factors within the line that contribute as a problem. All these factors were studied through an extensive application of time and motion study and line balancing technique to assess the assembly line.

\section{MATERIALS AND METHODS}

In order to meet a more efficient productive line, the three pillars shown in the figure was considered such 
as improving the cycle time, balance the line, and allocate optimal headcount to increase profitability of the company.

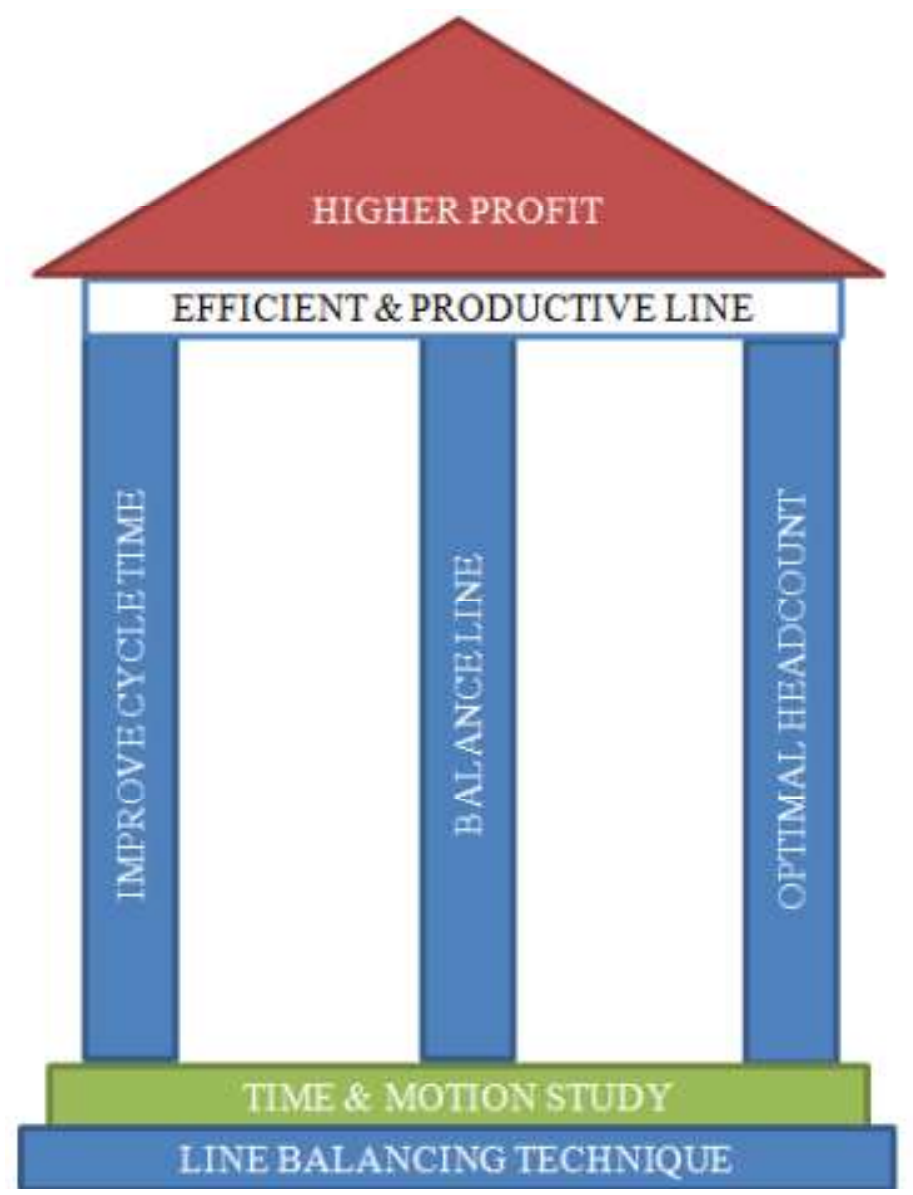

Figure1. Conceptual Framework of the study

This study uses descriptive method of research wherein data were gathered through actual observations and interview questionnaires regarding the operations within the assembly line were administered to the operators of the line including the Line Leader, Supervisors, Production Engineers and
Manager. Furthermore, the following tools were used as instrumentation of the study: Fishbone diagram to deeply analyze the root causes of the problems and relationships on how they contribute in affecting the assembly line; Pareto Diagram to graphically understand the occurrence of problems in each processes by ranking them into the most frequent and in order to find out which is the most contributing factor to problem within the sewing line; Time and Motion study to measure and record the existing cycle time of the operation and analyze the deficiencies in the existing cycle time of the operation and compute and set alternative standard time for the line; and Work Sampling Method to determine the amount of work, and delay, through work observation at random time.

\section{DISCUSSION AND RESULTS}

For three (3) months of observation, some factors that affect the productivity of a sewing line were noted such as manpower, material or product, process and method of operation. Historical data of the previous weeks of operation of the line regarding their output per regular eight working hours per day were also looked into. Variation of garments being processed in the line was also considered as basis of assessing the present operation of the line. The results of time study done was assessed based on the current standards and actual observations in the line.

Current set up of one of the cluster in a sewing line of the garment company in terms of distance and transportation time between operations was shown in the table below.

Table1. Actual distance and time consumed in a line

\begin{tabular}{|c|c|c|c|c|}
\hline $\begin{array}{l}\text { NVA's per } \\
\text { Operation }\end{array}$ & Movement Description & $\begin{array}{l}\text { Current } \\
\text { Distance } \\
\text { (Meter) }\end{array}$ & $\begin{array}{l}\text { Average } \\
\text { Observed } \\
\text { Time (sec) }\end{array}$ & $\begin{array}{l}\text { Total Time } \\
\text { Consumed } \\
\text { (sec) }\end{array}$ \\
\hline \multirow{3}{*}{1} & Going to Cut Goods Storage & \multirow{3}{*}{4.82} & 17.969 & \multirow{3}{*}{148.62} \\
\hline & Getting\& searching for Cut Goods & & 112.805 & \\
\hline & Going back to the Table & & 17.848 & \\
\hline \multirow{3}{*}{2} & Going to Cut Goods Storage & \multirow{3}{*}{4.82} & 17.361 & \multirow{3}{*}{113.25} \\
\hline & Getting \& searching for Cut Goods & & 99.497 & \\
\hline & Going back to the Table & & 16.39 & \\
\hline \multirow{3}{*}{3} & Going to Operator 5 & \multirow{3}{*}{5.115} & 12.882 & \multirow{3}{*}{28.961} \\
\hline & Getting Supply & & 4.501 & \\
\hline & Going back to the machine & & 11578 & \\
\hline
\end{tabular}


Table 2: Current Task Time of Operation in a Sewing Line

\begin{tabular}{|c|l|c|}
\hline Process no. & \multicolumn{1}{|c|}{ Process Description } & Task Time (Min) \\
\hline 1 & Press fuse back neck + Shoulder x2 & 0.476 \\
\hline 2 & Press fuse at sleeve Arm x2 & 1.155 \\
\hline 3 & Join Shoulder x2 & 0.404 \\
\hline 4 & Attach Sleeve at Arm Hole x2 & 1.144 \\
\hline 5 & Close Sleeves \& sides x2 & 1.105 \\
\hline 6 & 1" Fold Bottom x1 & 0.784 \\
\hline 7 & 1" Fold Sleeve Opening Arm x2 & 0.683 \\
\hline 8 & Attach Piping to bottom front Center x2 & 0.601 \\
\hline 9 & Basting + Insert Piping End at Bottom x2 & 0.667 \\
\hline 10 & Bend back Piping Bottom front Center x2 & 0.758 \\
\hline 11 & Attach front-neck Piping cont. x1 & 0.672 \\
\hline 12 & Make Label & 0.189 \\
\hline 13 & Attach main label to back neckline & 0.497 \\
\hline 14 & Basting + Insert Piping End at front neck x2 & 0.667 \\
\hline 15 & Bend back front-neck Piping cont x1 & 0.918 \\
\hline 16 & Stitch lock Bend back End 4x & 0.417 \\
\hline 17 & Attach Side Label & 0.436 \\
\hline & & $\mathbf{1 1 . 5 7 3}$ \\
\hline
\end{tabular}

The table above showed the current task time of each process in one of the clusters of sewing line of which was 11.573 minutes per garment, and currently used as the basis of computing the target output and productivity level of the line. The standard time of operation was measured plus the allowance factor of Twenty percent $(20 \%)$ which was set by the GSD (General Sewing Development) Department.

Table 3: Current Task Time of Operation \& Average Time of Ten Trials of Observation of Time Study

\begin{tabular}{|c|l|c|c|}
\hline Process no. & \multicolumn{1}{|c|}{ Process Description } & Task Time (Min) & $\begin{array}{c}\text { Time } \\
\text { Time }\end{array}$ (Min: Task \\
\hline 1 & Press fuse back neck + Shoulder x2 & 0.476 & 0.46 \\
\hline 2 & Press fuse at sleeve Arm x2 & 1.155 & 0.29 \\
\hline 3 & Join Shoulder x2 & 0.404 & 0.87 \\
\hline 4 & Attach Sleeve at Arm Hole x2 & 1.144 & 1.14 \\
\hline 5 & Close Sleeves \& sides x2 & 1.105 & 1.96 \\
\hline 6 & 1" Fold Bottom x1 & 0.784 & 1.33 \\
\hline 7 & 1" Fold Sleeve Opening Arm x2 & 0.683 & 0.59 \\
\hline 8 & Attach Piping to bottom front Center x2 & 0.601 & 0.64 \\
\hline 9 & Basting + Insert Piping End at Bottom x2 & 0.667 & 0.67 \\
\hline 10 & Bend back Piping Bottom front Center x2 & 0.758 & 0.93 \\
\hline 11 & Attach front-neck Piping cont. x1 & 0.672 & 0.70 \\
\hline 12 & Make Label & 0.189 & 0.23 \\
\hline 13 & Attach main label to back neckline & 0.497 & 0.62 \\
\hline 14 & Basting + Insert Piping End at front neck x2 & 0.667 & 0.85 \\
\hline 15 & Bend back front-neck Piping cont x1 & 0.918 & 0.91 \\
\hline 16 & Stitch lock Bend back End 4x & 0.417 & 0.42 \\
\hline 17 & Attach Side Label & 0.436 & $\mathbf{1 3 . 9 1}$ \\
\hline
\end{tabular}

According to the result of the ten (10) trials f observation of time study, it was found out that the currentn or existing task time of operation of a Sewing Line whichh was 11.573 minutes did not match the observed time of 13.91 minutes. The current and existing task time of operation of a sewing Line was not updated and did not fit to the actual processing time of operation in the line. 
International Journal of Trend in Scientific Research and Development (IJTSRD) ISSN: 2456-6470

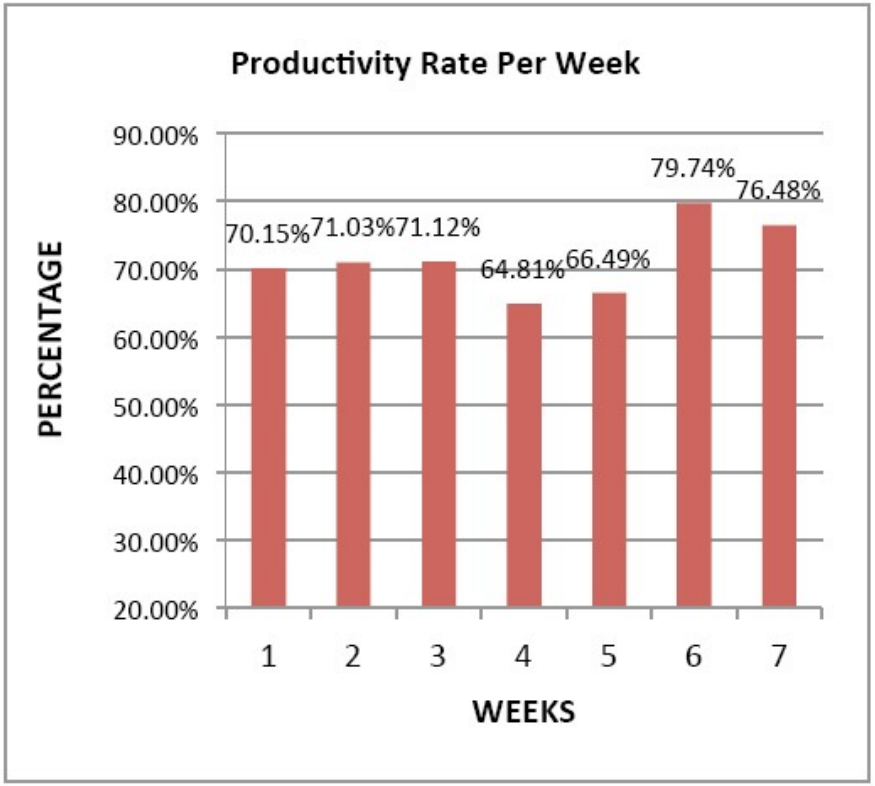

Figure 2: Productivity Rate per Week of a Sewing Line

Figure 2 showed the inconsistency of productivity level of a Sewing Line which productivity level averages to only seventy-one percent $(71 \%)$ and the highest productivity rate of the line per week was eighty percent (80) as reflected in the output per day which was the set target output of four hundred thirtyfive (435) units per day. The average output produced per day was four hundred ninety-nine (499) units wherein an average of five (5) hours overtime per day was allocated in order to meet the desired output and an average of seventeen units (17) units per hour were lost due to inefficiency of the line.

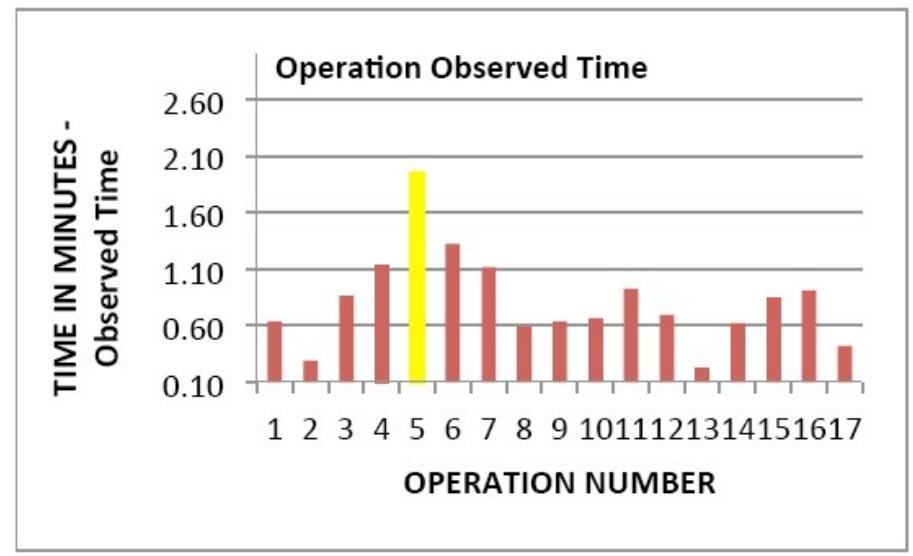

Figure 3: Bottleneck Operation of a Sewing Line

Figure 3 showed the time per process, the longest processing time of the line which was in operation 5 (close sleeves and sides) and the shortest was process 13 (attach main label to back neckline).

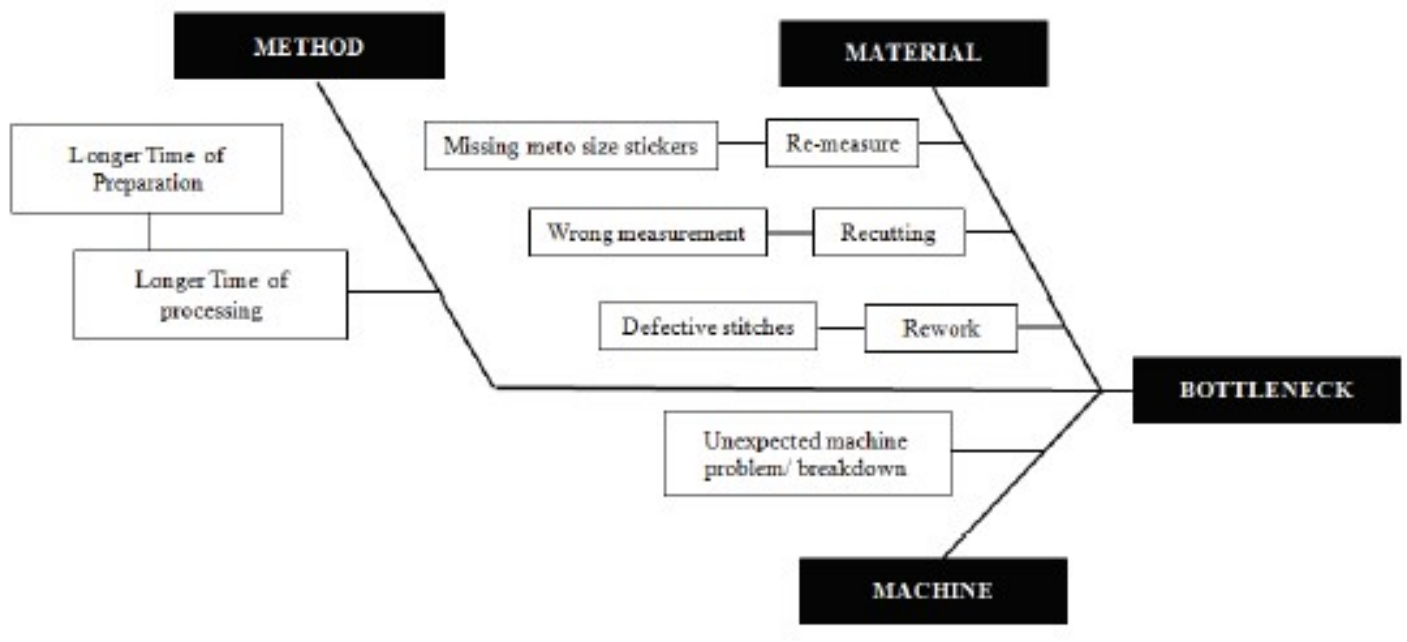

Figure4. Factors Affecting Bottleneck

Figure 4 showed the factors contributing to bottleneck based on the observation and interview conducted by the researchers in the line. Under this method, longer time of processing was rooted to the longer time of preparation of parts of the garment which was considered as non-value adding activity. For material, re-measuring due to missing meto-size stickers, recutting due to wrong measurement of the cut-goods and rework due to defective stitches was observed.
For machine, unexpected machine problem or breakdown was observed. There was no problem in manpower because all operators were regular workers and been working for almost ten (10) to twenty (20) years in the company which meant that they were already professional sewers and pressers. The factor over environment was disregarded since the facility was sufficiently ventilated and supplied with enough lighting. 
Using work sampling technique for 5 days observation, it was identified that the most frequently occurring problem in the line among all the observed factors causing bottleneck in a sewing line was the time of preparation of cut goods such as pairing and aligning of parts during sewing operations which averages to 126 times per day and averagely consumes 44.09 minutes per day.

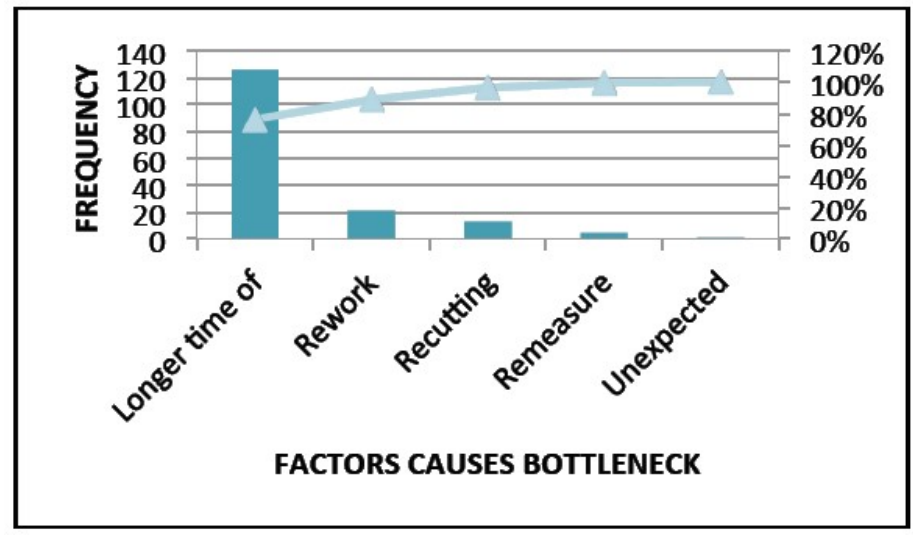

Figure 5: Occurrence of Factors Causing Bottleneck

Using Pareto Analysis, it was identified that the most contributing factor that caused bottleneck was the longer time of preparation of cut goods supply in the line.

\section{CONCLUSIONS AND RECOMMENDATIONS}

Based on the findings of the study, it can be concluded that the current standard time used in the Sewing Line was not updated and did not fit the current processing time of the line base on the 10 trial time study observation. An improper line layout of the line was not appropriate for cut goods storage, sewing machines and pressing machines due to distance travelled caused travel distance and improper process flow. Longer process time in pairing and aligning of cut goods was the most conttributing factor that causes bottleneck which did not add value to the operation.

Also, since the normal time of operation of the line was outdated according to time study results, it would be better to update it to new standard time where proper setting of target output would be obtained. After assessing the possible alternatives in treating the root cause of bottleneck of the line which was the longer time of preparation such as pairing and aligning of the cut goods, it can be concluded that one possible solution was to combine processes that have same machine requirements in order to reduce the preparatory time of pairing and aligning. Since balancing of the line through distribution of workload in each process was impossible due to different machine requirements per process, right manpower alignment and distribution would balance the operation of the line.

Updated standard time of operation in a Sewing Line gave it a proper baseline of computing for the target output. The existing twenty (21) operators could also be reduced into optimal eighteen (18) workers. Also, combination of process 4 and 5 was effective in reducing the time consumed by pairing and aligning parts of garments which was considered as non-value adding activity of the process, thus making the combined process more productive than the uncombined process. The new layout of the Sewing Line, where cut goods storage sewing machines and pressing machines were rearranged according to process sequence made the processing and product flow more smooth, thus helped eliminate and reduce travel distance consuming time. The current standard time and the proposed standard time of operation set in a Sewing Line was significantly different, thus the proposed standard time helped set a proper baseline in measuring the target output for the line and set optimal manpower allocation for the line to meet higher productivity.

For the next phase of improvement, it is recommended to to adopt 5's (Sort, Standardized, Set in order, Shine, Sustain) to properly control the flow of materials in the line by proper sorting of cut goods and to reduce the non-value adding activity such as preparation of cut goods due to unorganized flow of materials.

\section{REFERENCES}

1. Aadarsh Adeppa (2015), A Study on Basics of Assembly Line Balancing. International Journal on Emerging Technologies, 294-297.

https://www.google.com.ph/url?sa $=$ t\&rct $=\mathrm{j} \& \mathrm{q}=\&$ esrc $=$ s\&source $=$ web\&cd $=1 \&$ cad $=$ rja\&uact $=8 \& v e$ $\mathrm{d}=$ ahUKEwiE2cbQjovXAhWBs5QKHVr_CoMQ FggkMA\&url=https\%3A\%2F\%2Fwww.researchg ate.net $\% 2$ Ffile.OstFileLoader.html $\% 3$ Fid $\% 3 \mathrm{D} 56 \mathrm{a}$ 3580161432504bf8b481\%26assetKey\%3DAS\%2 53A321007137558528\%2540453545473420\&usg $=\mathrm{AOvVaw0B036OP} 3 \mathrm{sOiBB} 4 \mathrm{nSY}$ cwthr 
2. Aasheet Kumar1, Gaurav Chaudhary2, Manish Kalra3, \& Binit Kumar Jha (2014). Optimization Of Cycle Time For Wire Harness Assembly Line Balancing And Kaizen Approach. International Journal of Innovative Research in Science, Engineering and Technology, 3(8), 1-8. https://www.ijirset.com/upload/2014/august/36_O ptmization.pdf

3. Abdul Talib Bon \& Daiyanni Daim (2010). Time Motion Study In Determination Of Time Standard In Manpower Process. 3rd Engineering Conference on Advancement in Mechanical and Manufacturing for Sustainable Environment, 1-6. https://core.ac.uk /download/pdf/12008172.pdf

4. Balaji Rathod, Prasad Shinde, Darshan Raut, Govind

Waghmare (May 2016). Optimization of Cycle Time by Lean Manufacturing Techniques-Line Balancing Approach. International Research in Applied Science \& Engineering Technology, 4(5), 224-

226.http://www.ijraset.com/fileserve.php?FID=46 30

5. Chowdury M.D. \& Luthfur Rahman (2010). ReBalancing of Generalize Assembly Line Searching Optimal Solution for SALBP. Industrial Engineering and Operation Management Journal, 548-553.

http://www.ieomsociety.org/paper/252\%20Luthful . $\mathrm{pdf}$

6. D. Roy \& D. Khan (December2008). Assembly LineBalancing to Minimize Balancing Loss an System Loss. 6(11), 15.

http://www.iaujournals.ir/article_511022_a2ba368 003a70efca7951de4b512f0b.pdf

7. Fatemeh Mohebalizadehgashti (2016). Balancing, Sequencing and Determining the Number and Length of Workstations in a Mixed Model Assembly Line. A Thesis presented to The University

Guelph,1134.https://atrium.lib.uoguelph.ca/xmlui/ bitstream/handle/10214//Mohebalizadehgashti_Fat emeh_201605_Msc.pdf?sequence $=1$

8. F.Mercan (2012). Balancing Mixed Model Assembly Lines in an Automotive Supplier by Reconfiguring Layout. Thesis for Graduate School of Natural and Applied Sciences of Dokuz Eylul University,
199.http://www.fbe.deu.edu.tr/ALL_FILES/Tez_ Arsvi/2012/yl_t3073.pdf

9. Gantner, Karl (2016). Production Leveling and Cycle Time Reduction in Satellite Manufacturing. Leaders for Global Operations Program at MIT, $50-$

52.https://dspace.mit.edu/handle/1721.1/104217

10. M. Guner, O. Yucel and C. Unal (2012). Applicability of Different Line Balancing Method in the Production of Apparel. pp 7784.http://dergipark.gov.tr/download/articlefile/ 22000

11. Mihir R. Prajapati \& Vivek A. Deshpande (2015). Cycle Time Reduction Using Lean Principles and Techniques. International Journal of Advance Industrial Engineering, 3(4), 208213.http://inpressco.com/wpcontent/uploads/2015/ 12/Paper2208-213.pdf

12. Naveen Kumar \& Dalgobind Mahto (2013). Assembly Line Balancing: A Review of Developments and Trends in Approach to Industrial Application. Global Journal of Researches in Engineering, 13(2.1), 123.https://globaljournals.org/GJRE_Volume13/4Assembly-Line-Balancing-A-Review-of.pdf

13. Neda Manavizadeh (2013). A Simulated Annealing Algorithm for a Mixed Model Assembly U- Line Balancing Type-I Problem Considering Human Efficiency and Just-In-Time Approach. Computers and Industrial Engineering Journal,64(2), @ IJTSRD | Available Online@ www.ijtsrd.com | Volume - $1 \mid$ Issue - 5 | August 2017 Page: 6 669685.http://www.sciencedirect.com/science/article /pii/SO360835212002884

14. Pranavi Yerasi (August 2011). Productivity Improvement of a Manual Assembly Line. Office of Graduate Studies of Texas A\&M University,61.http://oaktrust.library.tamu.ed/bitstr eam/handle/1969.1/ETD-TAMU-2011-08-

10133/YERASI-THESIS.pdf? sequence $=2$

15. Puteri, Yuniaristanto, Hisjam (2017). Optimal Manpower Allocation in Aircraft Line Maintenance (Case in GMF Aeroasia). AIP Conference Proceedings 1902, 1902(1). http://aip.scitation.org/doi/abs/10.1063/1.5010625 ?ai $=1$ gvoi\&mi $=3$ ricys $\&$ af $=\mathrm{R} \&$ 
International Journal of Trend in Scientific Research and Development (IJTSRD) ISSN: 2456-6470

16. R. Bhagirath (2015). Rationalization of Manpower in Cutting Section. Dissertation for Bachelor of Fashion Technology, 1-56. http://14.139.111.26/jspui/bitstream/1/111/1/Ratio nalization\%20of\%20Manpower\%20in\%20Cutting $\% 20$ Section $\% 20 \% 20 \% 20$.pdf

17. Raj, Matthew, Jose, \& Sivan (2016). Optimization Of Cycle Time in an Assembly Line Balancing Problem. Global Colloquium in Recent Advancement and Effectual Researches in Engineering, Science and Technology, 25, 11461153.http://www.sciencedirect.com/science/article /pii/S2212017316305850

18. Ranjith Raja (2015). Assembly Line Design And Balancing. Master of Science Thesis in the Master's programme Production Engineering, 143. http://publications.lib.chalmers.se/records/fulltext/ 220682/220682.pdf

19. Sarah Wallach (2016). The Headcount Planning Countdown to Success. http://www.peoplefluent.com/blog/headcountplanningstrategies-tactics

20. Subhash C Sarin (2016). A Survey of the Assembly LineBalancing Procedures. Production Planning \& Control, 9(5), $414 \quad 434$. https://www.researchgate.net/publication/2381677 75_A_survey_of_the_assembly_line_balancing_p rocedures

21. Stockholm, Dencker, \& Hansson (2011). Strategies forAssembly Line Re-Balancing with Focus on Level ofAutomation. Department of Production Engineering andManagement School of Industrial Engineering and Management, 196.http://www.ngps.se/documents/ELUX3_Abhir am_REDDAMEmre_OZUGUREL_THESIS.final $\% 20$ report.pdf

22. Subodh Patil Shriram Sane, Varsha Karandikar, \& Rahul Pulkurte (June 2014), Assembly Line
Balancing:A Case Study in Silencer Manufacturing. InternationalJournal of Current Engineering and Technology.Vol.4, No.3. http://inpressco.com/wpcontent/Uploads/2014/05/Paper731583-1586.pdf

23. T. Borregueroa, F. Masa, JL. Menéndeza, \& M.A.Barreda (2015), Enhanced Assembly Line Balancing and Scheduling Methodology for the Aeronautical Industry. The Manufacturing Engineering Society International Conference, 990-

997.https://core.ac.uk/download/pdf/81111351.pdf

24. Trujillo and Bertilisson (2016). Investigation of the Workforce Effect on an Assembly Line Using Multi-Objective Optimization. Bachelor's Degree Project in Automation Engineering Bachelor Level, 93.http://www.divaportal.se/smash/get/diva2:1049 466/FULLTEXT01.pdf

25. Tom Pape (2015). Heuristics and Lower Bounds for theSimple Assembly Line Balancing Problem Type 1:Overview, Computational Tests and Improvements. European Journal of Operational Research,240(1), $32-42$. http://www.sciencedirect.com/science/article/pii/S 0377221714005268

26. Yi-Jhen Lin, Chun-Ju Lin, \& Tiffany Y. Chen (2014), Assembly Line Balancing Problem of Sewing Lines in Garment Industry. International Conference on Industrial Engineering and Operations Management, 1215-1225 http://ieomsociety.org/ieom2014/pdfs/273.pdf

27. Yana Myronenko (2012). Productivity Measurement

and Improvement. Department of Real Estate and Construction Management, 149, 5-25. http://www.divaportal.org/smash/get/diva2:55158 1/fulltext01.pdf 